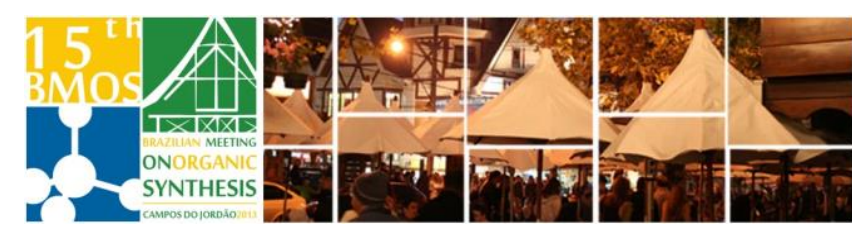

\title{
Directed Metalation of Aromatic Aldimines Using Li/Mg-TMP
} Amides

\author{
Cavalcante Silva,S.; Batista, J. H.;Moraes F.; Pereira, N. de A.; Clososki, G.C.
}

${ }^{a}$ Research Center for Natural and Synthetic Products, Faculty of Pharmaceutical Sciences of Ribeirão Preto - University of São Paulo

*simonecavalcante@pg.ffclrp.usp.br

Keywords: Aldimines, Magnesium, Metalation

\section{INTRODUCTION}

It has been reported in literature that metal based TMP bases are important reagents for the deprotonation of unsaturated substrates. ${ }^{1}$ In this work we describe our results on the directed metalation of $\mathrm{N}$-cyclohexyl aromatic aldimines with $\mathrm{Li} / \mathrm{Mg}$ TMP bases. Aldimines have attracted great attention by displaying a wide variety of biological activities. ${ }^{2}$ In addition, aldimines can be metalated and trapped with electrophiles and the resulting products can subsequently be converted to the corresponding benzaldehyde derivatives. ${ }^{3}$

\section{RESULTS AND DISCUSSION}

The aldimines were prepared by condensation of aldehydes with ciclohexylamine, providing the products with yields ranging from 90 to $95 \%$ (Scheme 1).<smiles>O=Cc1ccccc1C=O</smiles>

Scheme 1. Preparation of aldimines

Following these studies, we have investigated the metalation of aldimines with TMPLi and TMPMgCl.LiCl bases. The mixed $\mathrm{Li} / \mathrm{Mg}$ base was obtained through the direct reaction of $2,2,6,6$ tetramethylpiperidine (TMPH) with i-PrMgCl.LiCl (Scheme 2).

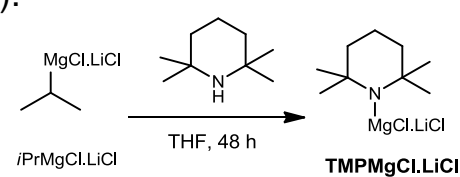

Sheme 2. Preparation of TMPMgCl.LiCl

A number of aromatic aldimines were metalated with the $\mathrm{Li} / \mathrm{Mg}$ TMP bases (Table 1). Reactions were carried out using $1 \mathrm{mmol}$ of substrates under different reactions conditions and with iodine as electrophile (Scheme 3). As observed in Table 1, according to the nature of the substrate the expected iodo-aldimines $(A)$ were obtained together with the corresponding iodo-aldehydes (B) due to the hydrolysis under the work-up.

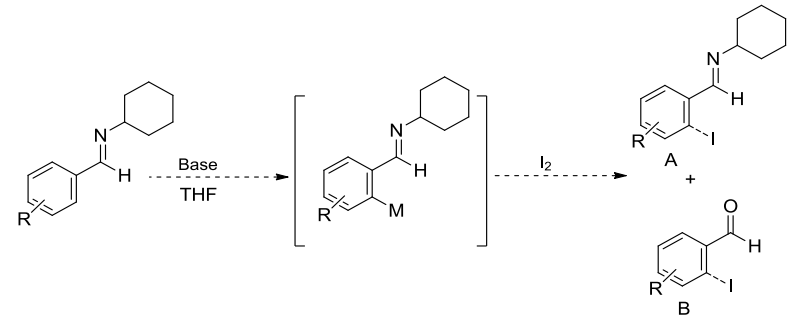

Scheme 3. Directed metalation of aldimines

Table 1. Products obtained by metalation of aromatic aldimines with subsequent trapping with iodine.

\begin{tabular}{|c|c|c|c|c|}
\hline Entry & $\mathbf{R}$ & Base & $\begin{array}{l}\mathrm{T}\left[{ }^{\circ} \mathrm{C}\right], \\
\mathrm{t}[\mathrm{h}]\end{array}$ & $\begin{array}{c}\text { Final product } \\
(\% \mathrm{~A}: \% \mathrm{~B})^{\star}\end{array}$ \\
\hline 1 & $3-\mathrm{OCH}_{3}$ & TMPLi & $-20,1$ & $59 \% A$ \\
\hline 2 & $3-\mathrm{OCH}_{3}$ & TMPMgCl.LiCl & t.a., 3 & $30 \% A$ \\
\hline 3 & $2-\mathrm{Br}$ & TMPLi & 0,2 & $58 \% A 11 \% B$ \\
\hline 4 & $2-\mathrm{Br}$ & TMPMgCl.LiCl & t.a., 1,5 & $20 \%$ A $27 \% B$ \\
\hline 5 & $2-\mathrm{Br}$ & TMPMgCl.LiCl & t.a., 2 & $33 \% A 10 \% B$ \\
\hline 6 & $3-\mathrm{Br}$ & TMPMgCl.LiCl & t.a., 2 & $27 \% A$ \\
\hline 7 & $3-\mathrm{Br}$ & TMPMgCl.LiCl & t.a. 3 & $8 \% A$ \\
\hline 8 & $4-\mathrm{Br}$ & TMPLi & 0,2 & $20 \% A$ \\
\hline 9 & $4-\mathrm{Br}$ & TMPMgCl.LiCl & t.a., 1 & $29 \% A 19 \% B$ \\
\hline 10 & $4-\mathrm{Br}$ & TMPMgCl.LiCl & t.a., 2 & $55 \% A 33 \% B$ \\
\hline 11 & $4-\mathrm{Br}$ & TMPMgCl.LiCl & t.a, 3 & $28,4 \mathrm{~A} 41,4 \mathrm{~B}$ \\
\hline 12 & $4-\mathrm{Br}$ & TMPMgCl.LiCl & 50,2 & $45 \%$ A $8 \% B$ \\
\hline 13 & $2-\mathrm{F}$ & TMPMgCl.LiCl & t.a. 2 & $57 \% B$ \\
\hline 14 & $2-F$ & TMPMgCl.LiCl & t.a., 3 & $35 \% B$ \\
\hline 15 & $4-\mathrm{F}$ & TMPMgCl.LiCl & t.a, 2 & $40 \% B$ \\
\hline 16 & $4-\mathrm{F}$ & TMPMgCl.LiCl & 50,2 & $25 \% B$ \\
\hline
\end{tabular}

${ }^{\star}$ Conversion.

\section{CONCLUSION}

$\mathrm{Li} / \mathrm{Mg}$-TMP amides appear to be interesting reagents for the metalation of aromatic aldimines. In addition, it may be an interesting method for the preparation of functionalized aldehydes. Our ongoing work aims to improve reaction yields and apply the methodology to the synthesis of bioactive molecules.

\section{ACKNOWLEDGEMENTS}

CAPES, CNPQ and FAPESP

\section{REFERENCES}

${ }^{1}$ Krasovskiy, V.; Krasovskaya, V.; Knochel, P.; Angew. Chem. 2006, 118 3024

${ }^{2}$ Brown, A. D.; Colvin E. V., Tetrehedron Lett . 1991, 32, 5

${ }^{3}$ Flippin, L. A.; Muchowski, J .M.; Carter, D. M. J Org. Chem. 1993, 58 2463

$15^{\text {th }}$ Brazilian Meeting on Organic Synthesis - $15^{\text {th }}$ BMOS - November 10-13, 2013 - Campos do Jordão, Brazil 